mass of information found in English publications, and partly in official archives.

In theinterval between the two "Afghanistan" books appeared "A History of Exploration from the Earliest Times to the Present Day" (1934). The volume covers a vast field and is particularly helpful in the chapters on Central Asia, the area on which the author ever kept a watchful eye. As a supplement to it came "The Quest for Cathay" (1936), popularizing the data of the Hakluyt series.

If to this enumeration of the principal works we add a number of occasional articles in the Royal Central Asian Journal, etc., and prefaces to the jointeffort books and translations, we shall recognize how well Sir Percy employed the leisure hours of his busy official life and the years of his retirement. His contribution to the knowledge of the Middle East and its manifold problems has been considerable and conspicuous.

V. Mrnorskx.

\section{Prof. L. I. Mandelstam}

Prof. L. I. Mandelstam, an outstanding Russian physicist and member of the Academy of Seiences of the U.S.S.R., died in Moseow on November 27, 1944, when at the height of his powers. Mandelstam was endowed with an unusually profound and subtle mind. He was at once a brilliant experimenter, an outstanding theoretical worker, a profound thinker, especially interested in the problems of epistemology and of the philosophy of science, and an outstanding expert in radio-engineering.

Mandelstam was born in 1879 in the south of Russia. He was educated at the University of Strassburg, where he began his scientific career as Prof. F. Braun's assistant; he became a Privatdozent in 1907 and obtained the title of professor in 1913. Together with N. D. Papalexi, his life-long collaborator, he carried out in that period a number of physical and technical researches of importance to the new subject of radio-engineering. He was the first to demonstrate the advantages of weak coupling (1904), which has since received wide practical application; he developed the method of the excitation of aerials with a prescribed phase difference (1906), and originated other technical advances.

Mandelstam's characteristic ability to discover deep inner ties between apparently unconnected phenomena soon directed his attention to another branch of physics, namely, optics, and particularly to the problem of the scattering of light, which throughout his life remained of prime interest to him. Mandelstam was the first to demonstrate, in 1907 , that the lack of optical homogeneity of the medium is the necessary condition for the molecular scattering of light which is due to radiation of atomic oscillators vibrating with definite phase relationships. This fundamental conclusion cleared the way for establishing the fluctuating nature of scatter ; Mandelstam himself followed up this work with a statistical theory of scattering of light on the surface of a liquid (1913). A number of other beautiful researches in optics were carried out during this period.

In 1914, Mandelstam returned to Russia, and his most creative period was the last twenty years of his life, after his election to a professorship in the University of Moscow in 1925 and to the membership of the Academy of Sciences in 1929. Mandelstam's lectures at Moscow were unsurpassed examples of university teaching, in which the borderline between teaching and creative scientific research vanished; not infrequently, during these lectures, problems originated that became later the subjects of scientific investigations.

Mandelstam's researches in the physics of oscillations were now given a new impetus. A master of the classical theory of oscillations, Mandelstam was clearly aware of its limitations and realized the necessity for developing a new 'non-linear' system of ideas and methods, that would be adequate to the new problems suggested particularly by the development of radio-engineering. He and his pupils searched persistently for these new methods, developing a theory of non-linear uscillations which gave fundamental results in the most varied branches of physics : radio, hydrodynamics, aerodynamies, the theory of automatic regulation and others. Mandelstam himself carried out a number of these important researches in collaboration with Papalexi, as for example the discovery of the phenomenon of resonance of the $n$-th kind, the so-called parametric filter based on this phenomenon, an important generalization of the conception of resonance, and the development of a new type of a generator of alternating current (the so-called parametrical machine).

Proceeding from optical analogies, Mandelstam and Papalexi invented radio interference devices, in particular the radio range-finder, by means of which precision measurements of the velocity of propagation of radio waves in varied conditions were carried out, and a new sphere of radio application developed, namely, radio-geodesy, which is now made use of in the Soviet Arctic regions as well as other parts of the U.S.S.R.

During the same period, Mandelstam and his collaborators carried out important optical investigations. Introducing into opties the conception of the modulation of oscillations, Mandelstam in 1918 came to the conclusion that the scattering of light must be accompanied by a change of frequency, conditioning the fine structure of scattered light. Experimental search for this phenomena led Mandelstam and Landsberg to the fundamental discovery of combinational scattering of light in erystals. Their first publication was dated May 6, 1928, and soon it became clear that the phenomenon discovered by them was of the same nature as the combinational scattering of light in fluids, simultaneously discovered by Raman, announced on March 31 of the same year, and since known as the Raman effect.

In the course of many further researches on the scattering of light, Mandelstam's attention was attracted to the absorption of ultra-acoustic waves. A relaxation theory of this phenomenon, developed by him in 1936, gave rise to a series of experimental researches in this direction.

Of late, Mandelstam's scientific interests turned primarily to the fundamental problems of quantum mechanics. He was the first to deduce the uncertainty relation between time and energy from the general formalism of quantum mechanics, and to reveal the simple physical meaning of this fundamental relation. In a course of his lectures on the theory of measurements of quantum systems, Mandelstam gave an interpretation of the theory unsurpassed in its clarity and depth ; in particular, he pointed out the fundamental distinction between direct and indirect measurements of quantum systems, which is of great importance to the further development of quantum theory.

Mandelstam's published works do not do justice 
to his many-sided scientific interests. He was generous in imparting his ideas to friends and collaborators, so that much which was really his appeared under another's name. Also, because of the very high standards that he demanded of himself, Mandelstam delayed, especially of late, the publication of his researches. For this reason much of his work will not be generally known until the posthumous edition of his collected works, which the Soviet Government has decreed, is published. His scientific researches earned him the Lenin prize, the Mendeléeff prize and the Stalin prize. For his general scientific and teaching work he was awarded the Order of the Red Banner and the Order of Lenin.

Mandelstam was a man of infinite kindness, possessed of great spiritual and intellectual charm that never failed to impress anyone who came into contact with him. Those who had the good fortune to know him more intimately will always cherish the memory of this scientific worker and man.

\section{P. Kapitza. \\ A. JoFrt. \\ S. VAVHLOV.}

WE regret to announce the following deaths:

Mr. R. W. F. Harrison, sometime assistant secretary to the Royal Society, on July 15, aged eightyseven.

Dr. J. C. Kernot, an authority on adhesives, on July 6, aged sixty-six.

Lieut.-Colonel J. C. Lamont, C.I.E., sometime professor of anatomy at Lahore Medical College, on June 19, aged eighty.

Prof. W. Makower, O.B.E., formerly professor of science at the Royal Military Academy, Woolwich, on July 7, aged sixty-five.

Dr. Catherine A. Raisin, formerly head of the Department of Geology, Bedford College for Women, University of London, on July 13, aged ninety.

Colonel C. H. D. Ryder, C.B., C.I.E., formerly surveyor-general of India, on July 16, aged seventyseven.

Dr. Alec Sand, F.R.S., physiologist to the Marine Biological Association since 1935, early in July, aged forty-three.

Mr. F. H. Todd, formerly of the Indian Forest Service, on July 9, aged seventy-one.

\section{NEWS and VIEWS}

\section{Prof. George Hevesy, For.Mem.R.S.}

Prof. George Hevesy celebrates his sixtieth birthday on August 1 in Sweden, where he is a guest of the Royal Swedish Academy of Science in Stock. holm. Members of the Academy have prepared a jubilee volume to mark the occasion. Prof. Hevesy and his family escaped from Denmark to Swoden when racial persecutions in Denmark and the tide of terrorism by the German occupants reached a climax in 1944. Prof. Hevesy is well known especially for his work on isotopes, including the early use of radioactive tracer atoms in investigations on diffuision in crystals and later on numerous biochemical problems, involving among others the study of the metabolism of phosphorus in organisms. His other great field of contributions to modern science is the discovery of the element hafnium, the chemical separation of hafnium from zirconium and the study of the properties of hafnium compounds. The relationship between hafnium and zirconium led him to the problem of the rare earth elements. Later, he developed quentitative analysis by means of his X-ray technique for the study of the geochemical frequency and distribution of numerous elements.

Prof. Hevesy, a Hungarian by birth, has held professorial chairs in Denmark (Copenhagen), in Germany (Freiburg-i.-B.) and from 1934 again in Denmark, where his work has been closely associated with the famous Institute of Theoretical Physics at Copenhagen directed by Niels Bohr. In-just recognition of his contributions, he was awarded the Nobel Prize for Chemistry for 1943. He has many ties with scientific men in Britain. For a period beginning in 1911, he worked in the late Lord Rutherford's laboratory when the latter was at Manchester. $\mathrm{He}$ frequently visited Britain to attend scientific meetings ; and in 1930 he gave the Hugo Müller Lecture before the Chemical Society. A number of British research students worked at his laboratories. Hevesy's many friends in Great Britain and elsewhere will be glad to know that he and his family are well, and will wish him many years of continued successful work and of happiness.

\section{Chair of Geography at Sheffield :}

Prof. R. N. Rudmose Brown

The retirement of Prof. R. N. Rudmose Brown from the chair of geography at the University of Sheffield at the end of this session marks the official end of nearly forty years of teaching and guiding university geography. His influence on the subject outside his university has been exercised through his being a member at one time or another of all the more important councils and committees which have to deal with geography, as well as through his books. Though he approached the subject from the point of view of a polar explorer and a naturalist, he has always insisted upon the essential unity of its physical and human aspects. His many contacts with French and other Continental geographers may have been the spur which caused him to become as notable a lecturer and writer on the human and economic aspects of his subject as the biological and physical side. His contribution to the recent advance of academic geography has therefore been based on the broadest grounds. This is reflected in his new building for his Department at Sheffield, which is second to none in Great Britain. Planned by him to serve with equal emphasis all the aspects of modern geography, it is a model which will be copied elsewhere in due course. As counsellor, examiner, writer, editor and practical explorer, Prof. Rudmose Brown has had an influence on geography which will endure. His rugged honesty of purpose and direct speech will be missed in many a council chamber, but it is quite certain that his years of retirement will often be interrupted by requests for advice from his younger colleagues, who will continue to be attracted by his wisdom and breadth of vision as well as by his long experience and commanding personality.

\section{Squadron-Leader David L. Linton}

SQUadron-Leader David L. LINToN, who succeeds Prof. Rudmose Brown at Sheffield, is thirty. eight years old, and was well known in British geographical science before the War. He had been 